\title{
Investigation of the effect of the family-centered empowerment model on the self-care ability of patients with colorectal cancer
}

\author{
Hojat Alah Nasri ${ }^{\circledR}{ }^{1}$, Ahmad Nasiri ${ }^{\left(D^{2}\right.}$, Seyed Vahid Hosseini ${ }^{(3}{ }^{3}$, Hajar khazraei ${ }^{3}{ }^{3}$, \\ Fahimeh Hajhosseini ${ }^{3}{ }^{3}$, Shahla Fereidooni ${ }^{3}{ }^{3}$, Gholamhossein Mahmoudirad ${ }^{4}{ }^{4}$
}

\begin{abstract}
Background and Aim: Colorectal cancer is a chronic disease that reduces the patients' quality of life. Therefore, it is essential to have self-care ability. This study aimed to investigate the effect of the family-centered empowerment model on the self-care ability of patients with colorectal cancer.

Materials and Methods: This randomized controlled study consisted of all patients who referred to the surgery ward of the colorectal clinic affiliated to Shahid Faghihi Hospital, Shiraz, Iran, during 2018. A total of 72 patients were selected by convenience sampling method and randomly allocated into control and experimental groups. A researcher-made questionnaire was used to collect data. It is worth mentioning that this study lasted nine months.

Results: The results showed a significant increase in the mean score of total self-care ability and its components in the experimental group, compared to the baseline after the intervention $(\mathrm{P}<0.001)$. In addition, the mean score of total self-care ability and its components was significantly higher in the control group after the intervention, compared to the pretreatment $(\mathrm{P}<0.05)$. Moreover, the experimental group obtained a significant increase in the score of total self-care ability and its components, compared to the control group $(\mathrm{P}<0.001)$. Eventually, the mean score of total self-care ability and its components, except for the visit component was significantly higher in the experimental group, compared to the control group after intervention $(\mathrm{P}<0.05)$.
\end{abstract}

Conclusion: The family-centered empowerment model can affect the self-care ability of patients with colorectal cancer. It is suggested that non-pharmacological interventions be combined with medical interventions in treatment plans.

Keywords: Colorectal Cancer, Family-Centered Empowerment Model, Self-Care

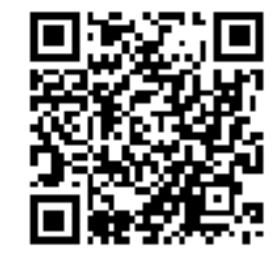

Citation: Nasri HA, Nasiri A, Hosseini SV, khazraei H, Hajhosseini F, Fereidooni SH, Mahmoudirad GH. [Investigation of the effect of the family-centered empowerment model on the self-care ability of patients with colorectal cancer]. J Birjand Univ Med Sci. 2020; 27(4):355-365. In press. [Persian]

DOI http://doi.org/10.32592/JBirjandUnivMedSci.2020.27.4.104

Received: January 20, 2020

Accepted: May 16, 2020

\footnotetext{
${ }^{1}$ Student Research Committee, School of Nursing and Midwifery Birjand University of Medical Sciences Birjand, Iran

2 Medical Toxicology and Drug Abuse Research Center (MTDRC), Department of Nursing, Faculty of Nursing and Midwifery, Birjand University of Medical Sciences, Birjand, Iran

${ }^{3}$ Colorectal Research Center, Department of Surgery, School of Medicine, Shiraz University of Medical Sciences, Shiraz, Iran

${ }^{4}$ Department of Medical Surgical Nursing, School of Nursing and Midwifery, Birjand University of Medical Sciences Birjand, Iran

Corresponding author: Department of Medical Surgical Nursing, School of Nursing and Midwifery, Birjand University of Medical Sciences Birjand, Iran Tel: +985632381401 
مقاله اصيل يخوهشى

\section{بررسى تأثير التكوى توانمندسازى خانوادهمحور بر توان خودمر اقبتى بيماران مبتلا به سرطان

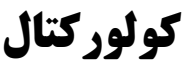

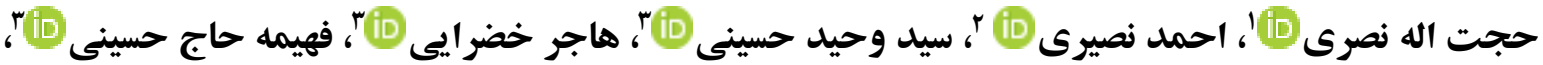

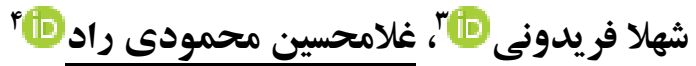

\section{جكيله}

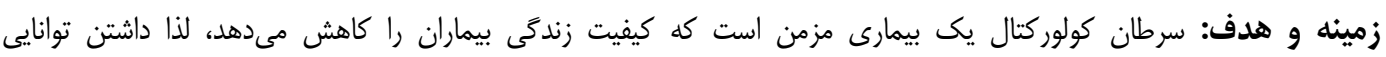

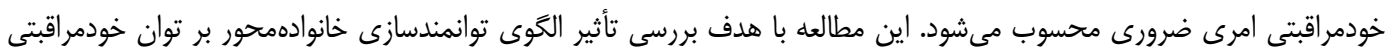

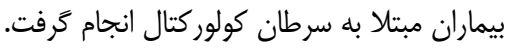

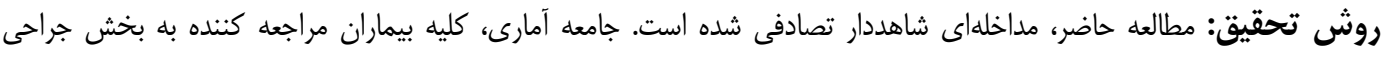

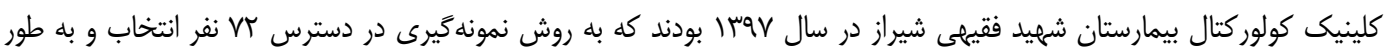

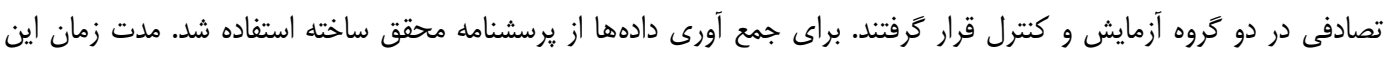
مطالعه 9 ماه بود.

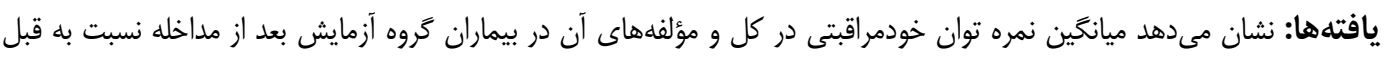

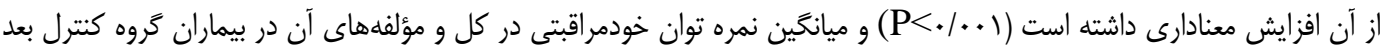

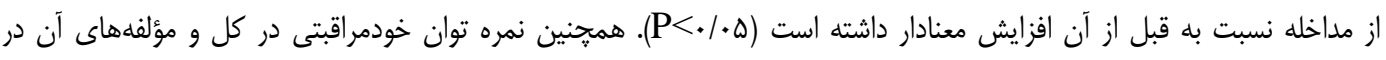

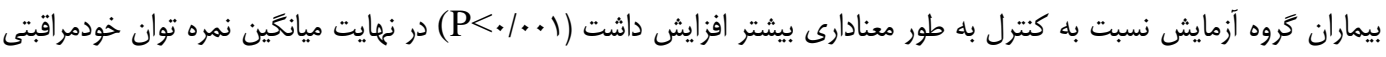

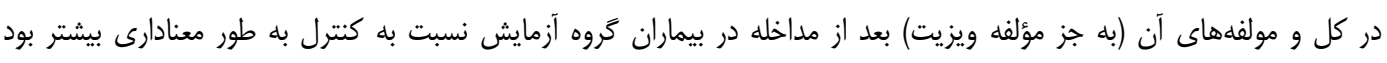

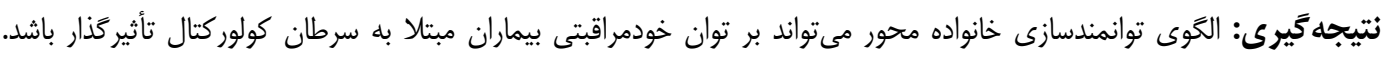

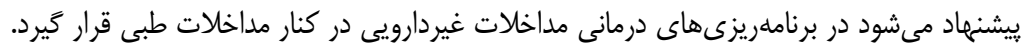

وازههاى كليدى: سرطان كولور كتال، الخوى توانمندسازى خانواده محور، خودمراقبتى

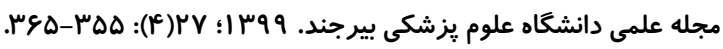

دريافت: • •

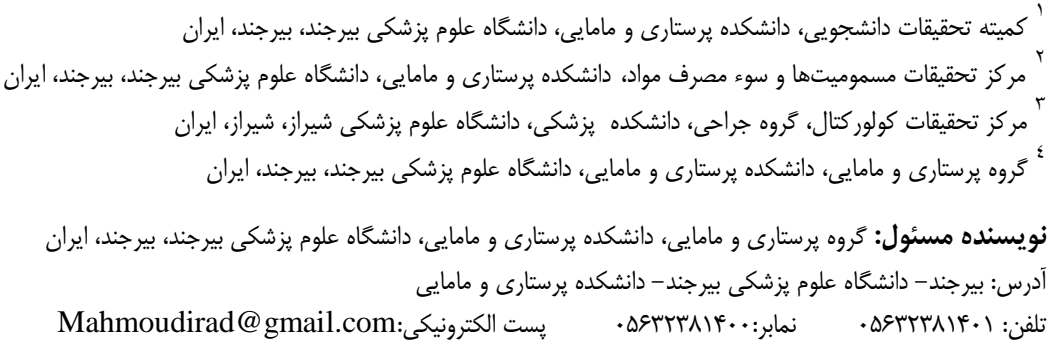


مزمن، مسئوليّت اصلى بر عهده خود بيمار و اطرافيان او مىباشد و نياز اندكى به استفاده از خدمات تخصصى وجود دارد. بنابراين توان

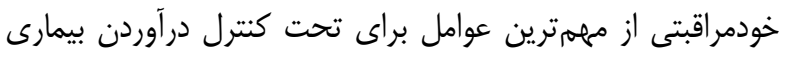

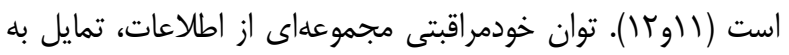

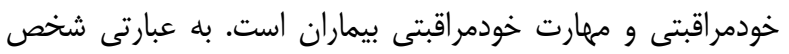
توانايى لازم را براى ايجاد تعادل بين توانايىهاى خود و نيازهاى

موجودى براى مراقبت از فرآيندهاى زندكى، كسب مىنمايد (سا).

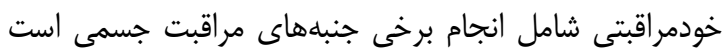

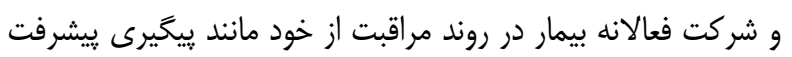

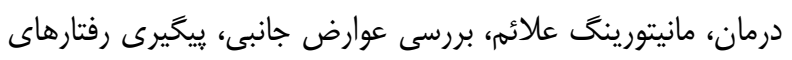

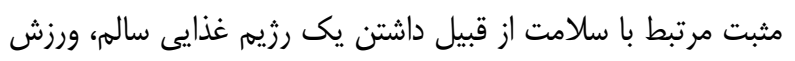

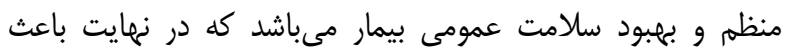

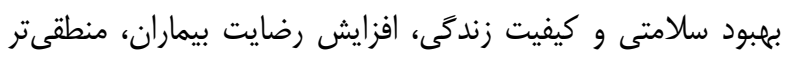
شدن استفاده از خدمات و كاهش هزينههاى سلامت مى شود (أl).

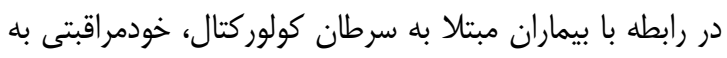

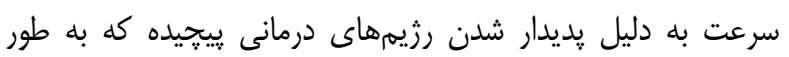

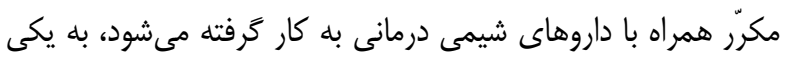

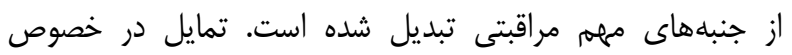

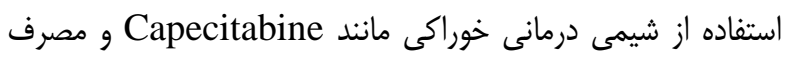
داروهاى خوراكى در خانه رو به افزايش است كه اين امر استفاده از

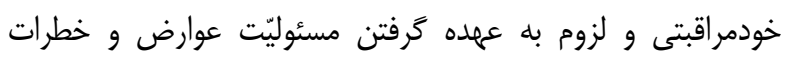

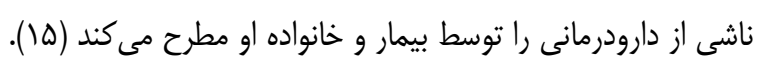

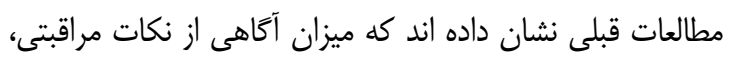
مهارت خودمراقبتى و توان خودمراقبتى در بيماران مبتلا به سرطان

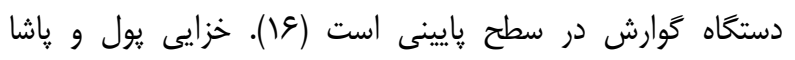

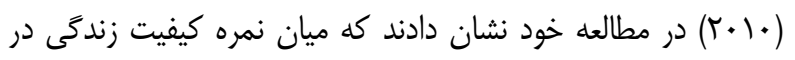

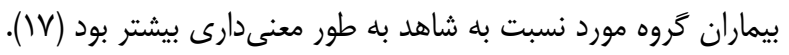

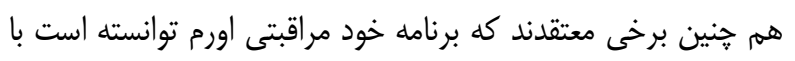
بهبودى معنى دار بعضى از علايم مرتبط با بيمارى و درمان، كيفيت

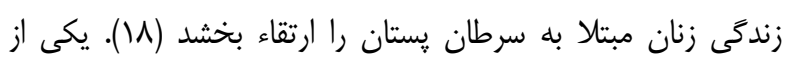

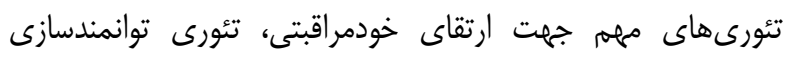
است. طبق اين تئورى مهمترين مؤلفهاى كه مىتواند منجر به ايجاد

\section{مقله}

امروزه سرطان يكى از معضلات مهم و اساسى بهداشت و

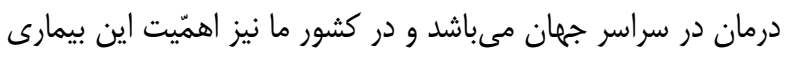
رو به افزايش است. از مهمترين سرطانها در سراسر دنيا سرطان كولوركتال است. اين سرطان از شايعترين سرطانهاى دستخاه

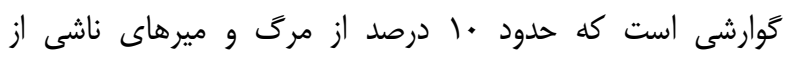
سرطان را به خود اختصاص مىدهد (ا) و در اثر رشد كنترل نشده

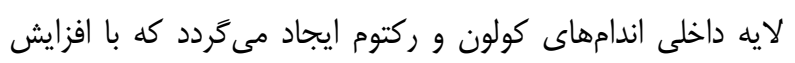
سن افزايش مىيابد به طورى كه نزديك به سَ/T بيماران در سنين ه9 سال يا مسنتر تشخيص داده مى شود (T). سرطان كولوركتال

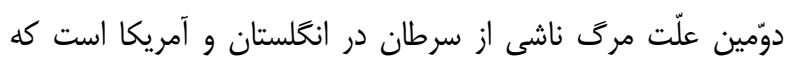

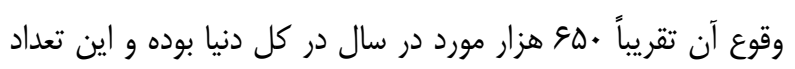

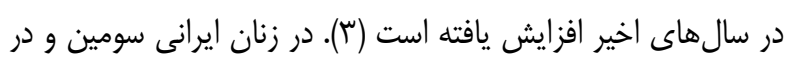

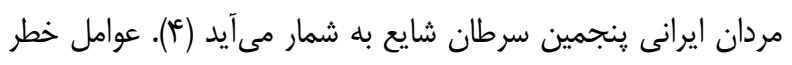

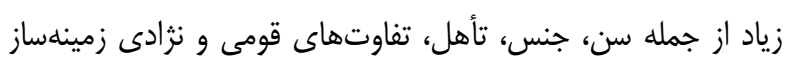

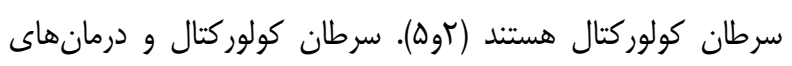
آن داراى عوارضى جون ضعف، خستخى، بى حالى، بى اشتهايى،

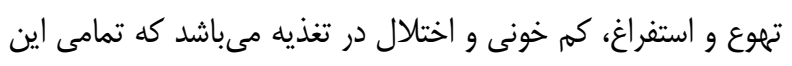

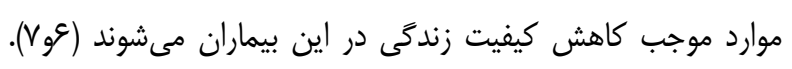

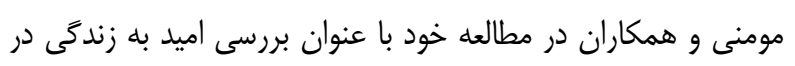
بيماران مبتلا به سرطان كولوركتال نشان دادند كه اكثر بيماران

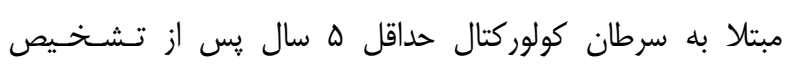
زنـــده مىمانند و كيفيت زندكى يايينى دارند (^).

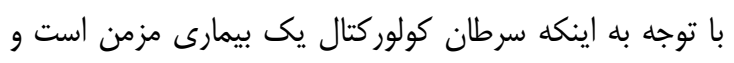

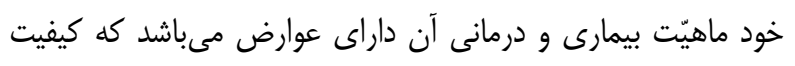

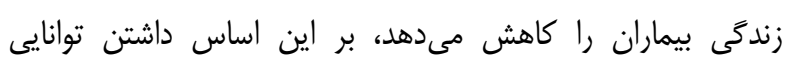

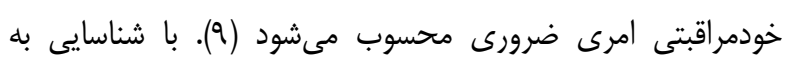

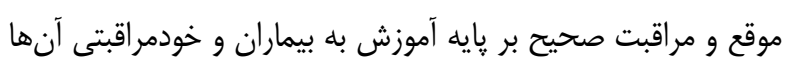

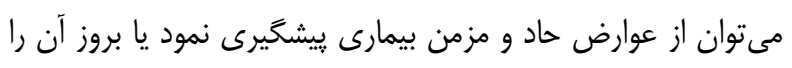
به تعويق انداخت. از نظر صاحبنظران عنصر حياتى در كنترل بيمارى آموزش و اتخاذ رفتارهاى خودمراقبتى است (• (1). مطالعات

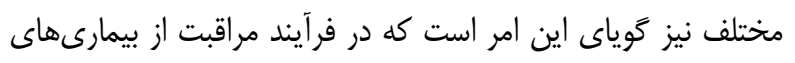




\section{روش تحقيق}

مطالعه حاضر، مداخلهاى شاهددار تصادفى شده است و بال شناسه IR.BUMS.REC.1397.090 به ثبت رسيده است. جامعه آمارى يزوهش حاضر شامل كليه بيماران مراجعهكننده به بخش جراحى كلينيك كولوركتال بيمارستان شهيد فقيهى شيراز با تشخيص قطعى سرطان كولوركتال در طى مدّت يزوهش در سال

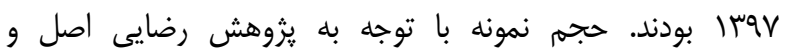

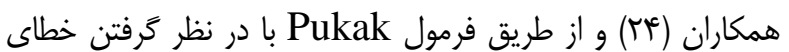

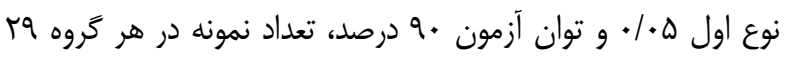

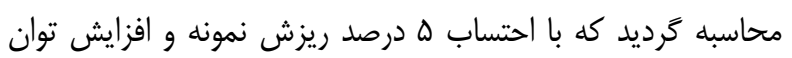

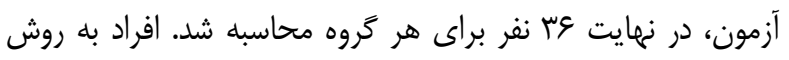

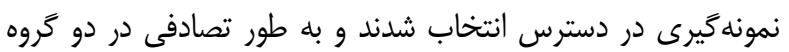
آزمايش (عس نفر) و گروه كنترل (عس نفر) قرار كرفتند.

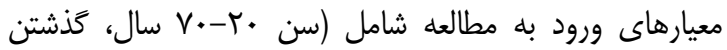
حداقل يك سال از تشخيص قطعى بيمارى، بيمارانى كه سابقه جراحى با تشخيص قطعى سرطان كولوركتال دارند، امكان مطالعه بيماران بعد از مرخصى از بيمارستان، امكان حضور حداقل يكى از لئرسان اعضاى خانواده بيمار در جلسات آموزشى، بيمار مشكلات اختلال يادكَيرى نداشته باشد، بيمار سواد خواندن و نوشتن داشته باشد، بيمار

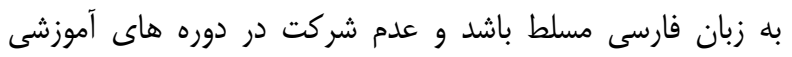

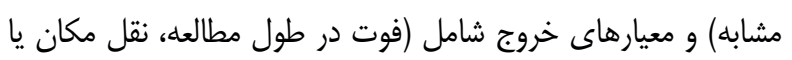
ادامه درمان در مراكزى خارج از شهر شيراز، عدم همكارى خانواده، غيبت در بيش از يك جلسه از جلسات آموزشى) بود. براى جمع آورى اطلاعات از دو يرسشنامه مشخصّات دموكرافيك (سن، جنس، وضعيت تأهّل، سطح تحصيلات) و وروات يرسشنامه سنجش توان خود مراقبتى محقق ساخته استفاده شد. يرسشنامه سنجش توان خود مراقبتى بيماران مبتلا به سرطان كولوركتال با مطالعه منابع و مقالات جديد در اين زمينه توسط مورد محقق در ه زمينه مراقبتهاى فيزيكى، روانى، هيجانى، مذهبى و

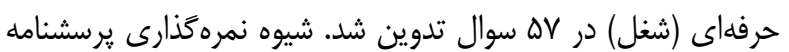

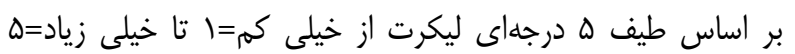

توانمندى در فرد شود، رفتار خودمراقبتى به عنوان يك الخو مىباشد

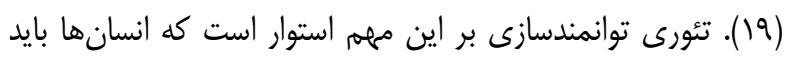
ظرفيت لازم براى تصميمَّيى را داشته باشند و از طرفى بتوانند

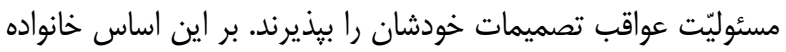
در جريان مراقبت از يك بيمار، نيازمند درك صحيح از بيمارى است

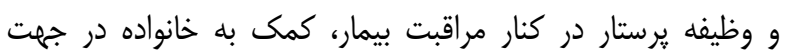
افزايش اميد و اعتماد است؛ جنين رويكردى باعث ارتقاى سلامت و

رفاه خانواده خواهد شد (· (r).

مراقبين كروهى از افراد هستند كه به علت فشارها و تقاضاهاى

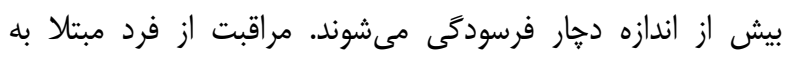
بيمارى مزمن، تنش زيادى براى مراقب و خانواده بيمار ايجاد

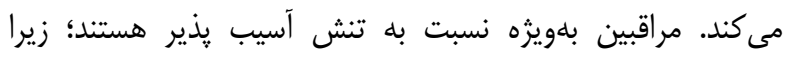

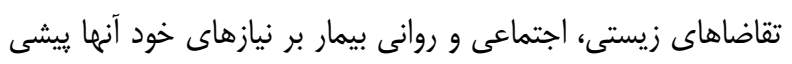

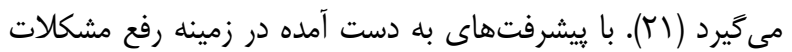
بهداشتى، مراقبين خانوادگى جايكزين مؤسّسات مراقبتى شده اند.

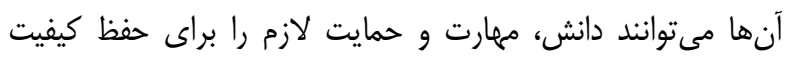
مراقبت در خانه فراهم كنند (T/). الكوى توانمندسازى خانوادهمحور

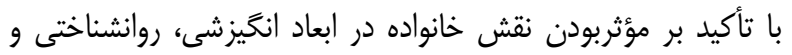

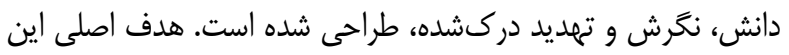
الكو توانمند شدن سيستم خانواده در جهت ارتقاء بهداشت مى نهباشد

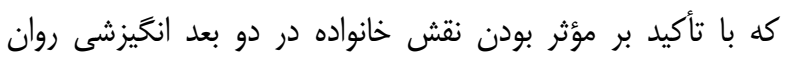

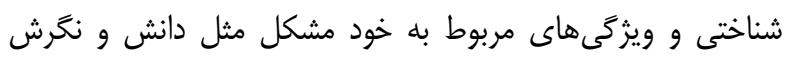

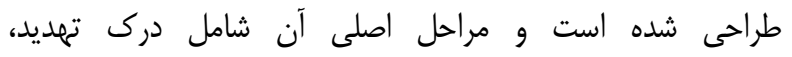

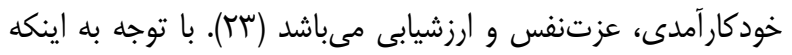

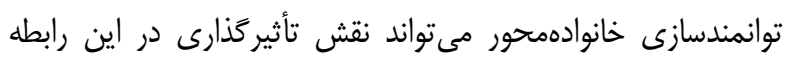
داشته باشد و طبق جستجوى علمى كه محقق انجام داد مطالعات محدودى در زمينه تأثير الكوى توانمندسازى خانوادهمحور بر برى خودمراقبتى بيماران مبتلا به سرطان كولوركتال انجام شده است. لذا اين مطالعه با هدف بررسى تأثير الكَى توانمندسازى خانوادهمحور بر بران توان خودمراقبتى بيماران مبتلا به سرطان كولوركتال انجام گرفت. 
كه در دو مرحله، يكى در بايان هر جلسه براى اطمينان از يادَّيرى

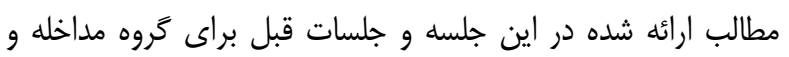
ديخرى در پايان بعد از مداخله براى هر دو كروه انجام شد.

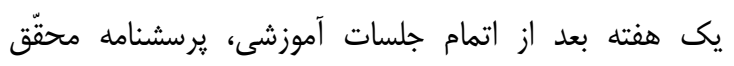
ساخته سنجش رفتارهاى خودمراقبتى توسط بيماران هر دو كروه تكميل شد. يس از تكميل يرسشنامه ها، براى تجزيه و تحليل از نرم افزار

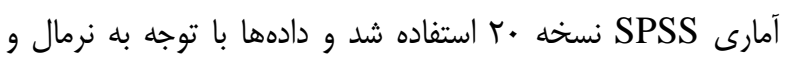
غير نرمال بودن، از آزمون هاى تى مستقل، زوجى، ويلكاكسون و

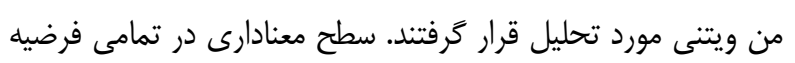
هاى تحقيق (ه./.

\section{يافته ها}

VT برسشنامه توصيف اطلاعات از حيث مشخصّات جمعيت

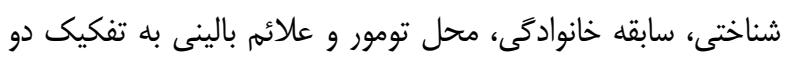
كروه در جدول شماره ا نشان داده شده است.

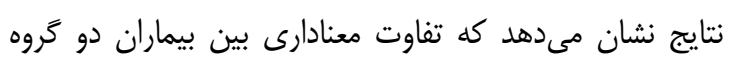

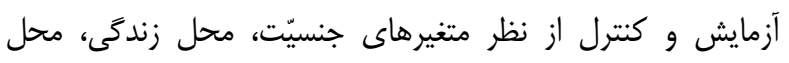

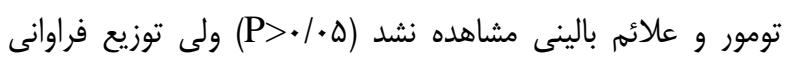

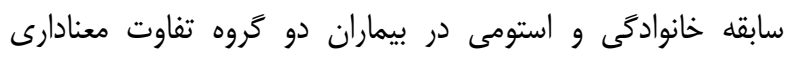

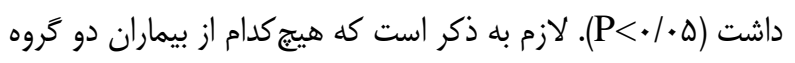
علايم ضعف و بى حالى و تهوّع و استفراغ نداشتند (جدول (1). نتايج ديخر نشان داد، ميانگين نمره توان خودمراقبتى در كل و مؤلفههاى

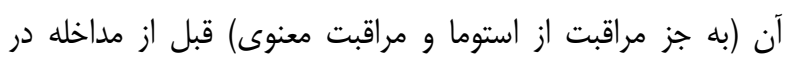

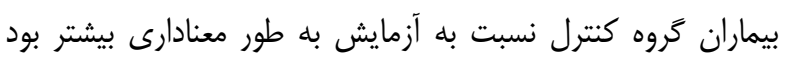

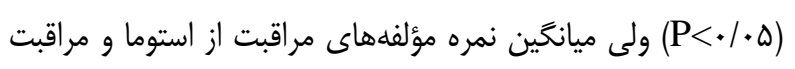

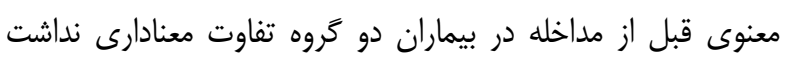
تمال

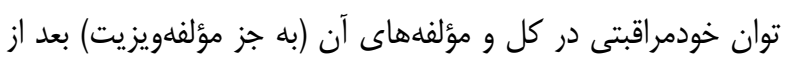

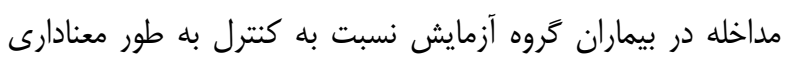

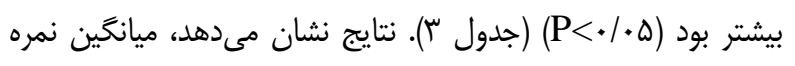

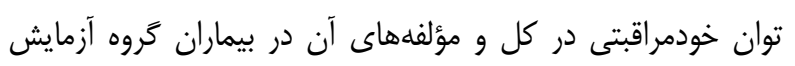

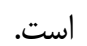

به منظور تأييد روايى، يرسشنامه در اختيار •ا نفر از اساتيد

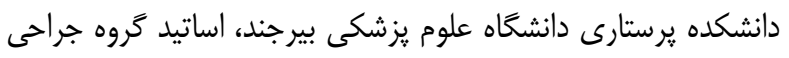

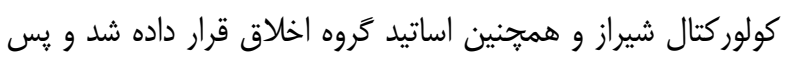

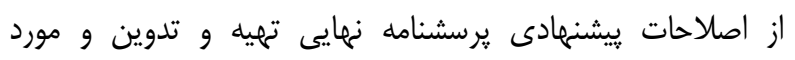

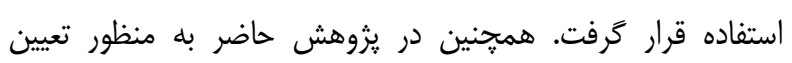

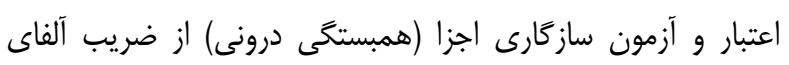

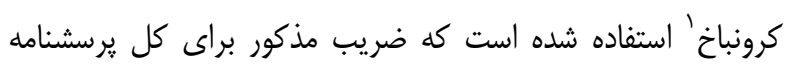

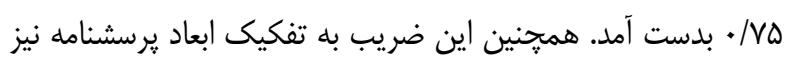

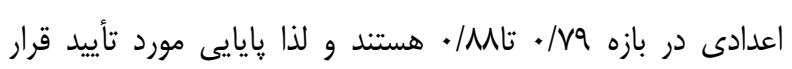
كرفت. - م

روش اجراى اين تحقيق بدين صورت است كه در ه جلسه به

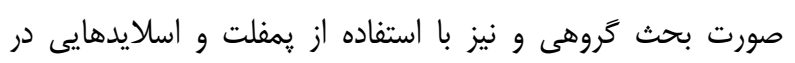

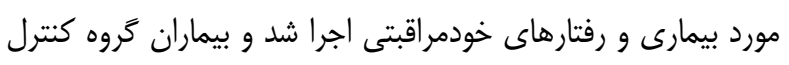
مداخلهاى دريافت نكردند. مراحل و گام هاى الخوى توانمندسازى

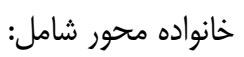
گام اول (درى تهلديد): اولين مرحله در الخوى توانمندسازى

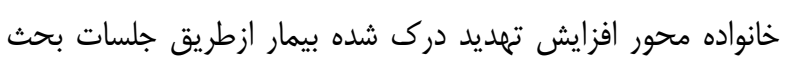
كروهى به منظور افزايش شدت و حساسيت درى شده مى مباشد.

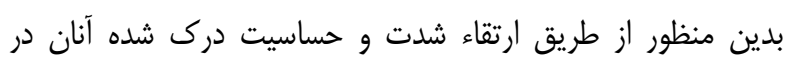

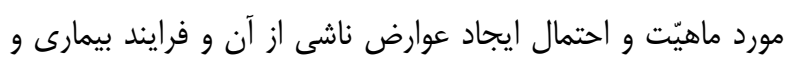

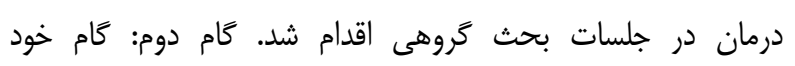

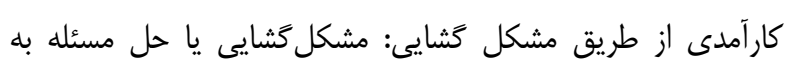

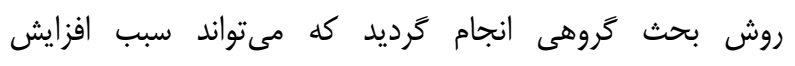

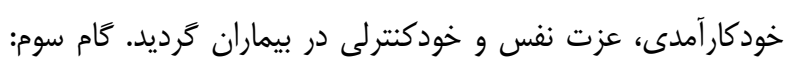

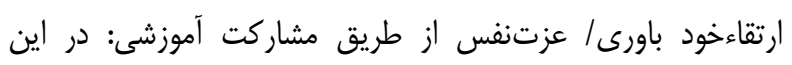

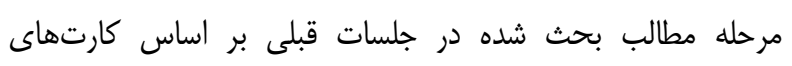

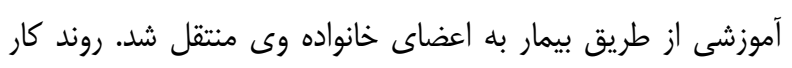

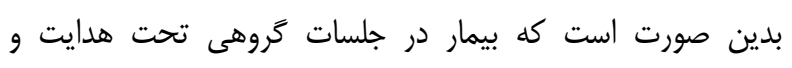

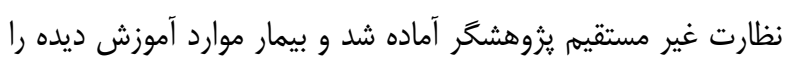
به عضو فعال خانواده خود آموزش داد. كام جهارم (ارزشيابى فرآيند):

\footnotetext{
${ }^{1} \alpha$-Cronbach
} 
(جدول ع). در نهايت نتايج نشان مىدهد، به طور متوسط نمره توان خودمراقبتى در كل و مؤلفههاى آن در بيماران كروه آزمايش نسبت ندان

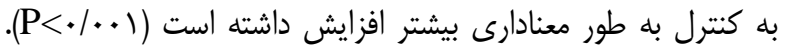

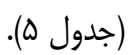

بعد از مداخله نسبت به قبل از آن افزايش معنادارى داشته است

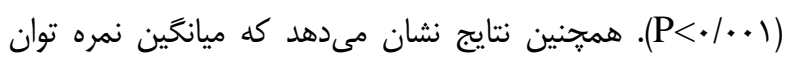

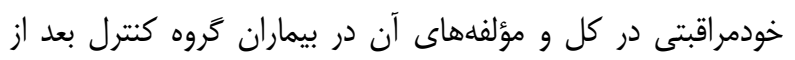

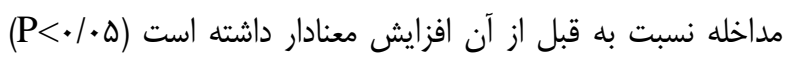

جدول (- مقايسه مشخصات جمعيّتشناختى، سابقه خانوادَّى، محل تومور و علائم بالينى در بيماران دو تَروه آزمايش و كنترل

\begin{tabular}{|c|c|c|c|c|c|}
\hline \multirow[t]{2}{*}{ سطح معنى دارى } & \multirow[t]{2}{*}{ آماره كاى دو } & كنترل & آزمايش & \multirow{2}{*}{\multicolumn{2}{|c|}{ متغير }} \\
\hline & & تعداد (درصد) & تعداد (درصد) & & \\
\hline \multirow{2}{*}{$\cdot|\wedge|$} & \multirow{2}{*}{.1 .09} & $(\xi \backslash / 1) \pi r$ & $(q \mu / q) r \mu$ & مرد & \multirow{2}{*}{ جنسيت } \\
\hline & & $(r N / q)$ IF & سו(I/) & زن & \\
\hline \multirow{3}{*}{.$/ 90$} & \multirow{3}{*}{$.1 .+r$} & (qr/q) r r & $(\varepsilon g / V) M r$ & شهر & \multirow{3}{*}{ محل زندكى } \\
\hline & & $(1 r / q) \Delta$ & $(1 r / q) \Delta$ & روستا & \\
\hline & & $(r / T) \wedge$ & $(19 / 4) V$ & بدون ياسخ & \\
\hline \multirow{3}{*}{$.1 \cdot 1=$} & \multirow{3}{*}{ s/a. } & $(F V / T) \backslash V$ & $(q 9 / \Gamma) \Gamma_{0}$ & ندارد & \multirow{3}{*}{ سابقه خانوادكى } \\
\hline & & r & $(N / r) r$ & 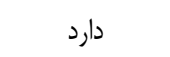 & \\
\hline & & $(19 / 4) \vee V$ & $(T r / T) \wedge$ & بدون ياسخ & \\
\hline \multirow{4}{*}{.$/ 01$} & \multirow{4}{*}{ 1/rg } & $(I \varepsilon / V) D$ & $(11 / 1) r$ & كولون راست & \multirow{4}{*}{ محل تومور } \\
\hline & & $(1 \cdot)^{r}$ & $(\Gamma / v) 1$ & كولون جِ & \\
\hline & & $(V / r / r) r r$ & سז & ركتوم & \\
\hline & & 8 & 9 & بدون ياسخ & \\
\hline \multirow{5}{*}{ ( ) } & \multirow{5}{*}{$r / 19$} & $(V / V) r$ & $(\tilde{c} / \Gamma) 1$ & درد شكمى & \multirow{5}{*}{ علائم بالينى } \\
\hline & & $(\xi 9 / T) \backslash \Lambda$ & $(99 / V) \backslash 9$ & ركتورازى & \\
\hline & & $\left(1 \Delta / F^{c}\right)^{\mathbb{C}}$ & $(r q / r) \vee$ & يبوست & \\
\hline & & $(V / V)^{r}$ & $(\cdot) \cdot$ & آنمى & \\
\hline & & 1. & ir & عدم باسخحَويى & \\
\hline \multirow{2}{*}{.$|+F|^{*}$} & \multirow{2}{*}{$\varphi / M$} & $(V V / \Lambda) r \Lambda$ & $(q F / F) \mu r$ & دارد & \multirow{2}{*}{ استومى } \\
\hline & & $(T / T) \Lambda$ & $(\Delta / \varepsilon) r$ & 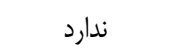 & \\
\hline
\end{tabular}

جدول ؟ - مقايسه ميانكَين نمره توان خودمراقبتى در كل و مؤلفههاى آن قبل از مداخله در بيماران دو تروه آزمايش و كنترل

\begin{tabular}{|c|c|c|c|c|}
\hline \multicolumn{2}{|c|}{ نتيجه آزمون آمارى } & آزمايش & كنترل & \multirow[t]{2}{*}{ تروه } \\
\hline سطح معنى دارى & $\mathbf{z} \mathbf{t} \mathbf{t}$ & ميانكيند|نحراف معيار & ميانكَين土|نحر اف معيار & \\
\hline.$/ .1$ & $r / \backslash \Lambda^{* * n}$ & $r / r \pm \cdot / V \Lambda$ & $r / \Delta \cdot \pm \cdot / 99$ & ر رزيم غذايى \\
\hline$<\cdot / \cdot \cdot 1$ & $r / \Delta F^{\text {with }}$ & $r / \mathscr{R}) \pm \cdot / V \zeta$ & $\Gamma / \Gamma \mid \pm \cdot / \varepsilon \Delta$ & مراقبت از زخم \\
\hline $.1 \cdot 14$ & $r / F D^{* *}$ & $r / \Delta \cdot \pm \cdot / / \mu$ & $r / 9 V \pm \cdot / 19$ & ويزيت \\
\hline .1 .91 & $1 / V^{*}$ & $r / Y V \pm \cdot / V Y$ & $\Upsilon / \cdot \cdot \pm \cdot / \wedge \Delta$ & مراقبت از استوما \\
\hline 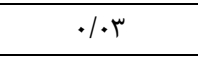 & $r / 1 \varphi^{* w *}$ & $r / 94 \pm . / 99$ & $r / \Lambda \gamma \pm \cdot / \Delta \Lambda$ & فعاليت بدنى \\
\hline.$/ . r$ & $r / 9 r^{* *:=}$ & $r / r \mu \pm . / V \varphi$ & $T / V \cdot \pm \cdot / q V$ & مراقبت روانى \\
\hline.$/ T M$ &.$/ \Delta Q V^{*}$ & $r / 9 \cdot \pm \cdot / 9 \mathrm{~V}$ & $r / V \& \pm \cdot / q r$ & مراقبت معنوى \\
\hline...$r$ & 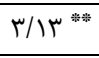 & $r / \Delta \& \pm \cdot / \Delta q$ & $r / Q Y \pm \cdot / 0 Q$ & مراقبت حرفهاى \\
\hline$<\cdot / \cdot \cdot \mid$ & $r /\left.\Delta\right|^{m *}$ & $r / 4 \& \pm \cdot / \Delta q$ & $r / \Lambda \Gamma \pm \cdot / \Delta r$ & توان خودمراقبتى در كل \\
\hline
\end{tabular}




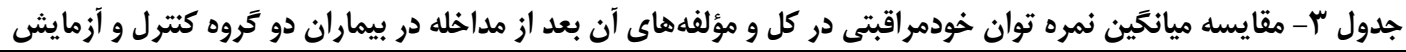

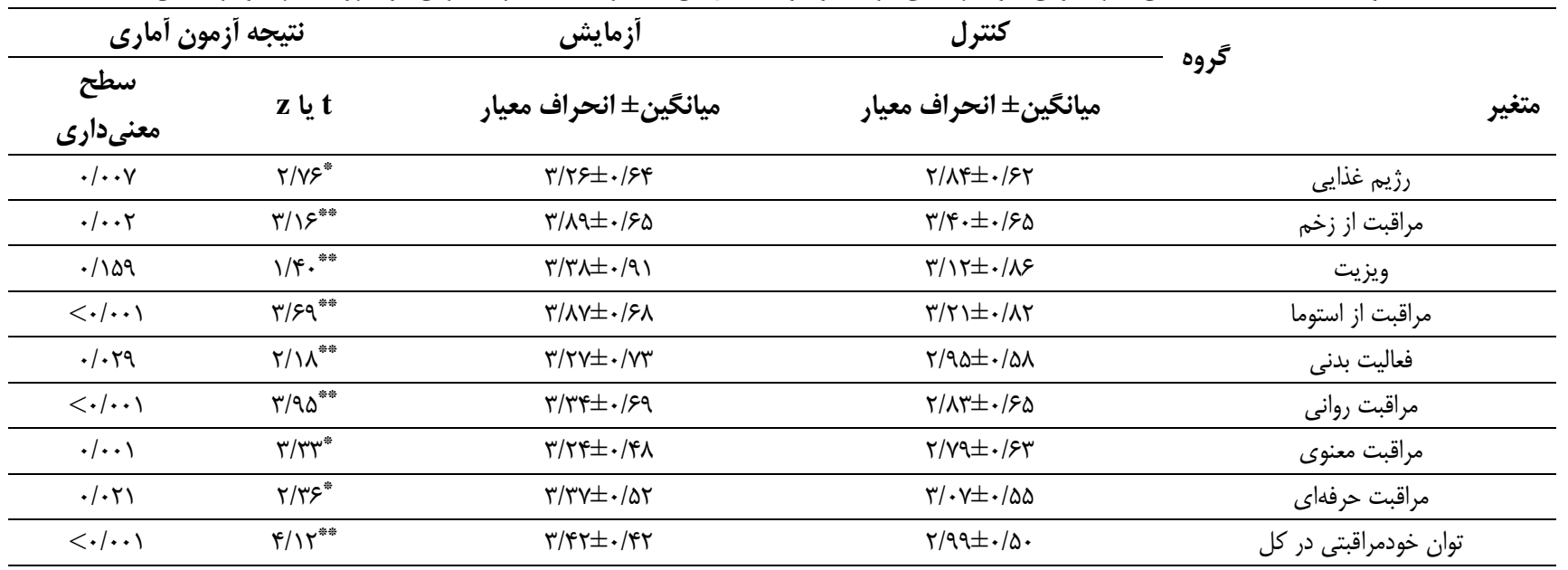

جدول f - مقايسه ميانكَين نمره توان خودمراقبتى در كل و مؤلفههاى آن قبل و بعد از مداخله در بيماران تروه آزمايش و كنترل

\begin{tabular}{|c|c|c|c|c|c|}
\hline \multicolumn{2}{|c|}{ نتيجه آزمون آمارى } & بعد از مداخله & قبل از مداخله & \multirow{2}{*}{ مرحله } & \multirow[t]{2}{*}{ كروه } \\
\hline معنىدارى سطح & $\mathbf{z}$ t & ميانخين土 انحراف معيار & ميانكيند انحر اف معيار & & \\
\hline$<\cdot / \cdot+1$ & $0 / \cdot 9^{* * * *}$ & $r / r q \pm \cdot / g r$ & $r / r \pm \cdot / V \Lambda$ & رزيم غذايى & \multirow{9}{*}{ كروه آزمايش } \\
\hline$<\cdot / . \cdot 1$ & $\Delta / \cdot 1^{* * * * *}$ & 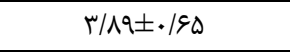 & $r / Y) \pm \cdot / V q$ & مراقبت از زخم & \\
\hline$<\cdot / \cdot \cdot 1$ & $F / V g^{\text {**:* }}$ & 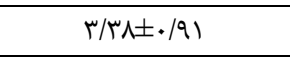 & $r / \Delta \cdot \pm \cdot / \Lambda r$ & ويزيت & \\
\hline$<\cdot / \cdot \cdot 1$ & $9 / 99^{*}$ & $r / \Lambda \vee \pm \cdot / \& \Lambda$ & $r / \& \vee \pm \cdot / V q$ & مراقبت از استوما & \\
\hline$<\cdot / \cdot+1$ & $Y / \Delta \Delta^{\text {**:* }}$ & $r / r V \pm \cdot / V r$ & $r / 9 Y \pm \cdot / 9 q$ & فعاليت بدنى & \\
\hline$<\cdot / \cdot+1$ & 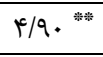 & $r / \mu r \pm . / q q$ & T/MUE./V & مراقبت روانى & \\
\hline$<\cdot / \cdot+1$ & $8 / \wedge \Delta^{*}$ & $r / r F \pm \cdot / \kappa \Lambda$ & $r / 9 \cdot \pm \cdot / q V$ & مراقبت معنوى & \\
\hline$<+1 \cdot+1$ & $\Delta / 1 \varphi^{* * * * *}$ & $r / r V \pm \cdot / \Delta r$ & $r / \Delta q \pm \cdot / \Delta q$ & مراقبت حرفهاى & \\
\hline$<\cdot / \cdot+1$ & $\Delta / 19^{* * * *}$ & r/ATE./RT & $r / 4 \& \pm \cdot / \Delta q$ & توان خودمراقبتى در كل & \\
\hline$<\cdot / \cdot+1$ & $\Lambda / T \Delta^{*}$ & $r / A r \pm \cdot / q r$ & $r / 0 \cdot \pm \cdot / 99$ & ر ريم غذايى & \multirow{9}{*}{ كروه كنترل } \\
\hline $.1 \cdot 14$ & T/AYF" & $r / \varphi \cdot \pm \cdot / q r$ & $\mu / \mu I \pm \cdot / 90$ & مراقبت از زخم & \\
\hline$<\cdot / \cdot+1$ & $\Gamma / \Delta V^{\text {***: }}$ & r/Irt./NE & $r / 9 \vee \pm \cdot / \wedge 9$ & ويزيت & \\
\hline$<\cdot / \cdot+1$ & 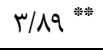 & $T / r \mid \pm \cdot / A r$ & $\Psi / \cdot \pm \cdot / \wedge \bowtie$ & مراقبت از استوما & \\
\hline $.1 . t r$ & $r / q^{* * * *}$ & $r / 9 \Delta \pm \cdot / \Delta \Lambda$ & $r / \Lambda V \pm \cdot / \Delta \Lambda$ & فعاليت بدنى & \\
\hline $.1+\cdots$ & r/ & $r / \Lambda r \pm \cdot / 9 \Delta$ & $r / V \cdot \pm \cdot / q V$ & مراقبت روانى & \\
\hline $.1 \cdot \mathrm{TV}$ & $r / \mu I^{*}$ & $r / V q \pm \cdot / q r$ & $r / V \& \pm \cdot / \& \mu$ & مراقبت معنوى & \\
\hline$<\cdot / \cdot+1$ & $1 / 4)^{*}$ & $r / \cdot V \pm \cdot / \Delta \Delta$ & $r / 9 r \pm . / 09$ & مراقبت حرفهاى & \\
\hline$<\cdot / \cdot \cdot 1$ & Q/K & $r / 99 \pm \cdot / 0$. & $r / \Lambda F \pm \cdot / \Delta F$ & توان خودمراقبتى در كل & \\
\hline
\end{tabular}




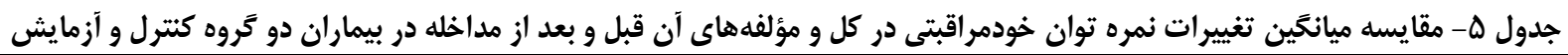

\begin{tabular}{|c|c|c|c|c|}
\hline \multicolumn{2}{|c|}{ نتيجه آزمون آمارى } & آزمايش & كنترل & تروه \\
\hline سطح معنىدارى & $z \mathbf{t} t$ & ميانكَين انحر اف معيار & ميانگيند انحراف معيار & متغير \\
\hline$<\cdot / \cdot+1$ & $\Delta / \Delta \varphi^{*}$ & $1 / \Gamma+ \pm \cdot / q$ & $\cdot / \mu \Psi \cdot / r r$ & رزيم غذايى \\
\hline$<\cdot / \cdot \cdot 1$ & $91 \cdot 1^{\text {wath }}$ & 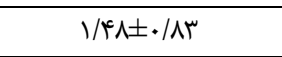 & $\cdot / .9 \pm \cdot / 10$ & مراقبت از زخم \\
\hline$<\cdot / \cdot \cdot 1$ & $\Delta / q^{\prime \prime=}$ & $\cdot / \wedge \wedge \pm \cdot / v q$ & $. / 1 \Delta \pm \cdot / r$ & ويزيت \\
\hline$<\cdot / . .1$ & $\Delta / \Delta \Delta^{* * w^{*}}$ & $I / T \cdot \pm \cdot / V T$ & $\cdot / T \pm \cdot / T V$ & مراقبت از استوما \\
\hline$<\cdot / . .1$ & $r / 9 \Delta^{\prime \prime \prime \prime}$ & $. / 94 \pm . / 91$ & $\cdot / \cdot \vee \pm \cdot / / \Lambda$ & فعاليت بدنى \\
\hline$<\cdot / . .1$ & $\Delta / \Psi^{4}$ & $1 / \cdot 1 \pm \cdot / v$ & $\cdot / / r \pm \cdot / 19$ & مراقبت روانى \\
\hline$<\cdot / . .1$ & $\Delta / 1 \Gamma^{-W=}$ & $. / 9 Y \pm \cdot / \Delta F$ & $\cdot / \cdot r \pm \cdot / \cdot 1$ & مراقبت معنوى \\
\hline$<\cdot / \cdot+1$ & $\Delta / q^{*}=$ & $\cdot / \Lambda \cdot \pm \cdot / \Delta \Delta$ & $. / 14 \pm . /$. & مراقبت حرفهاى \\
\hline$<\cdot / . .1$ & $\Delta / \phi^{*}$ & $. / 91 \pm \cdot / 94$ & $. / r \mu \pm . / \mu r$ & توان خودمراقبتى در كل \\
\hline
\end{tabular}

نشد. در اين مطالعه محل تومور در بيشتر بيماران دو كروه آزمون و

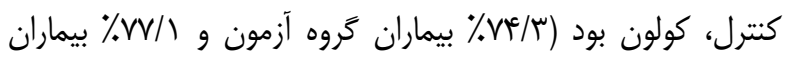

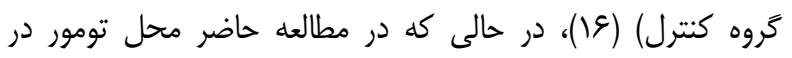
بيشتر بيماران دو كروه آزمايش (MN/9. بود. اگرجه در مطالعات كريمى و همكاران (ع) نوع مداخله و محل تومور متفاوت از مطالعه حاضر بود، ولى نتايج به دست آمده مشابه و مله حاكى از تأثير آموزش بر توانخودمراقبتى بيماران مبتلا به سرطان اصنان

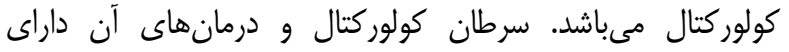

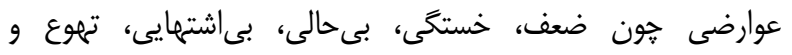
استفراغ، كم خونى و اختلال در تغذيه مىباشد كه تمامى اين موارد

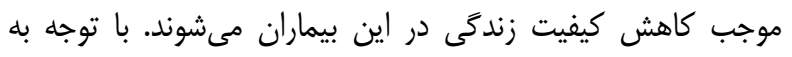

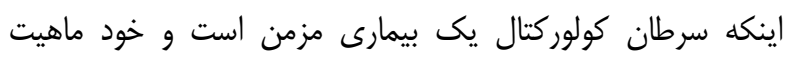
بيمارى و درمانى آن داراى عوارض مىباشد كه كيفيت زندمى ينى بيماران را كاهش مىدهد، بر اين اساس داشتن توانايى خود مراقبتى دانى

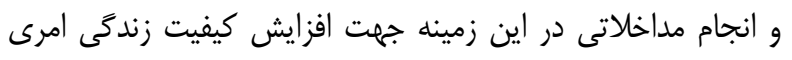

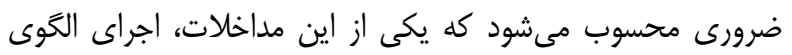

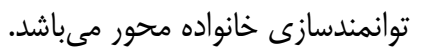
در اين راستا نتايج مطالعه شيروانى و همكاران در زمينه تاثير اجراى الكَوى توانمندسازى خانواده محور بر مقياسهاى عملكردى ميرى

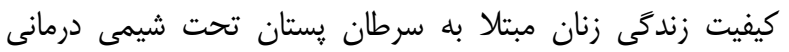

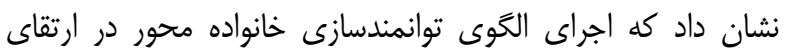

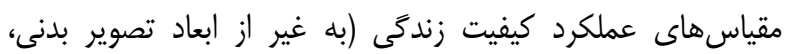

اين مطالعه با هدف تعيين تأثير الخَى توانمندسازى خانواده

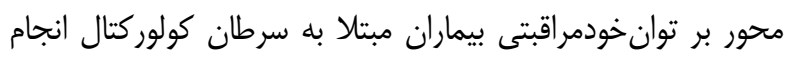

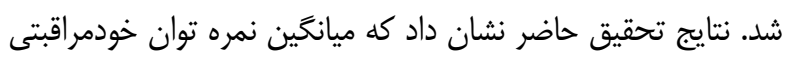

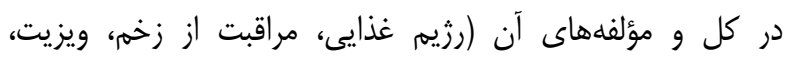

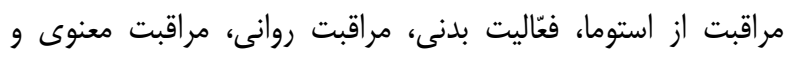

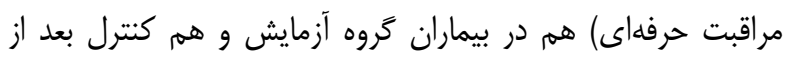

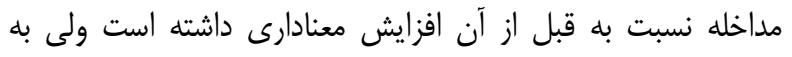

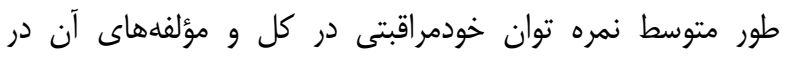
بيماران گروه آزمايش نسبت به كنترل به طور معنادارى بيش بيشتر

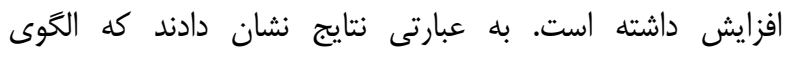
توانمندسازى خانواده محور مى تواند بر توانخودمراقبتى بيماران مبتلا به سرطان كولوركتال تاثير معنادارى داشته باشد. با جستجو در يايخاههاى اطلاعاتى، يُوهشى مشابه مطالعه حاضر كه به بررسى تاثير الكوى توانمندسازى خانواده محور بر توان

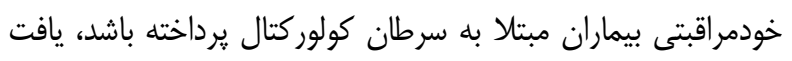
نشد ولى در مطالعهاى كه كريمى و همكاران داشتند به بررسى تأثير برنامه خودمراقبتى مبتنى بر الخوى اورم بر بهبود توان خودمراقبتى دمانى

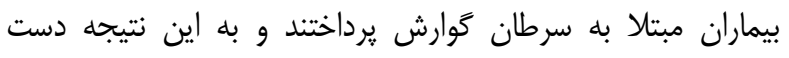

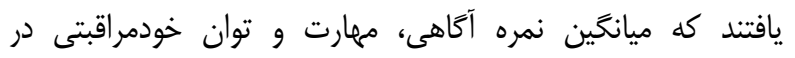

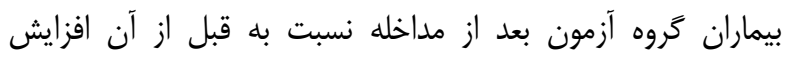
معنادارى داشته است. ولى در كروه كنترل تفاوت معنادارى مشاهده 
همجنين Yau و همكاران با استفاده از يك مطالعه طولى اثر ايجاد استوما را بر كيفيت زندگى مرتبط با سلامتى مبتلا به سرطان

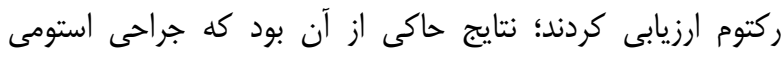

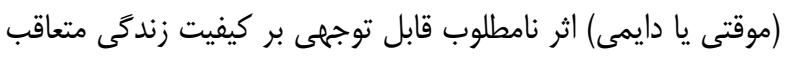

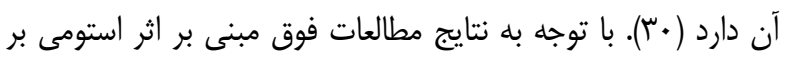

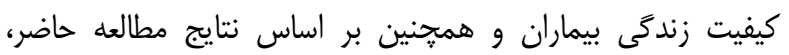

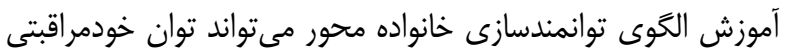

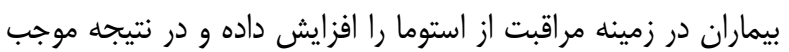

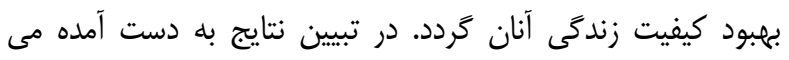

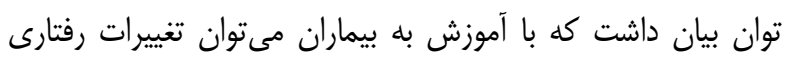
مناسبى در آنها ايجاد كرد.

\section{نتيجه كيرى}

همانطور كه نتايج مطالعه حاضر نشان داد الكوى توانمندسازى خانواده محور بر توان خودمراقبتى بيماران مبتلا به سرطان سطان كولور كتال موثر بوده است، لذا ييشنهاد مى شود در برنامهريزىهاى درمانى مداخلات غيردارويى در كنار مداخلات طبى قرار گيرد.

\section{تقدير و تشكر}

اين مقاله بر گرفته شده از پايان نامه كارشناسى ارشد يرستارى

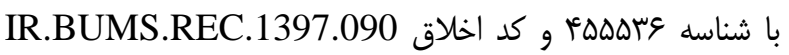
است. از بيماران و اساتيد كه در انجام اين مطالعه ما را يارى نمودند،

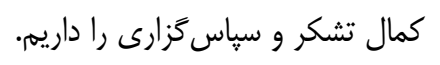

\section{تضاد منافع}

نويسندكان مقاله اعلام مىدارند كه هيج كَنه تضاد منافعى در

$$
\text { يزوهش حاضر وجود ندارد. }
$$

عملكرد جنسى و لذا جنسى) در زنان مبتلا به سرطان يستان مؤثر

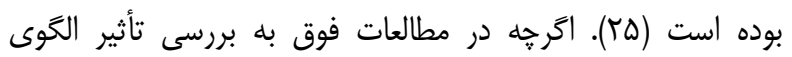

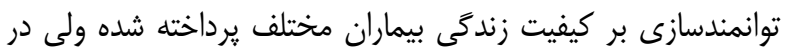

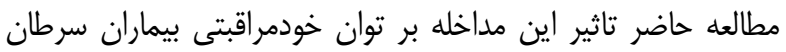
كولور كتال بررسى شده است ولى نتايج به دست آمده تقريبا مشابه و

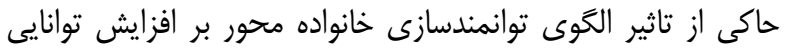
خودمراقبتى و در نتيجه ارتقاى كيفيت زندگى بيماران مىباشد. بر اساس نتايج مطالعه ديخر مشخص شد به دنبال اعمال جراحى در مبتلايان به سرطان ركتوم، سطح توانايى انجام فعاليتهاى روزانه به مقدار زيادى كاهش مى يابد و در بيدان بيماران مسن

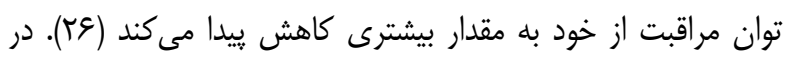
مطالعه حاضر آموزش الكَوى توانمندسازى خانواده محور علاوه نه ينه

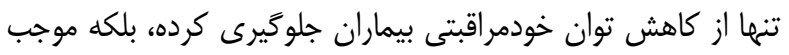
ارتقاى سطح توان خودمراقبتى بيماران شده است. نتايج يك مطالعه مرورى نشان داد كه توانمندسازى در بيماران مسن تحت عمل جراحى كولوركتال باعث بهبود فقاليتهاى فيزيكى هم (TV)

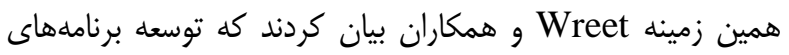
ورزشى در بيماران مبتلا به سرطان روى كيفيت زندكى اين بيماران

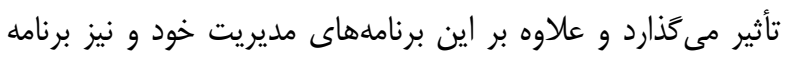
هاى افزايش خودكارآمدى روى برايند سلامت اين بيماران تاثيركذار

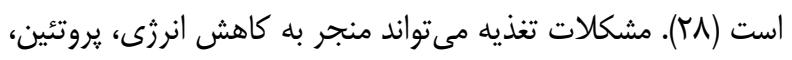

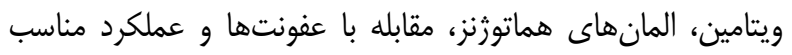

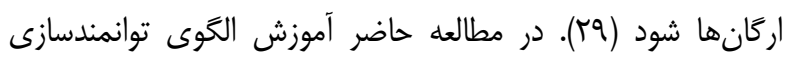
خانواده محور منجر به افزايش توان خودمراقبتى بيماران در زمينه

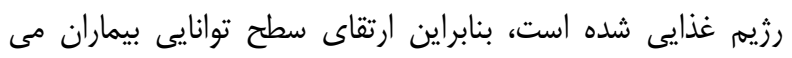
تواند از عوارض ناشى از كمبود موادّ غذايى ييشَّيرى كند.

1- Sun V, Grant M, McMullen CK, Altschuler A, Mohler MJ, Hornbrook, MC, et al. Surviving colorectal cancer: longterm, persistent ostomy-specific concerns and adaptations.J Wound Ostomy Continence Nurs. 2013; 40(1): 61. DOI: 10.1097/WON.0b013e3182750143.

2- Van Mossel C, Leitz L, Scott S, Daudt H, Dennis D, Watson H, et al. Information needs across the colorectal cancer care continuum: scoping the literature. Eur J Cancer Care (Engl). 2012; 21(3): 296-320. DOI:10.1111/j.13652354.2012.01340.x. 
3- Beech N, Arber A, \& Faithfull S. Restoring a sense of wellness following colorectal cancer: a grounded theory. J Adv Nurs. 2012; 68(5): 1134-1144. DOI: 10.1111/j.1365 2648.2011.05820.x.

4- Siegel R, DeSantis C, \& Jemal A. Colorectal cancer statistics, 2014. CA Cancer J Clin. 2014; 64(2), 104-117. DOI: $10.3322 /$ caac. 21220

5- Osmani F, Hajizadeh E, Rasekhi A and Akbari ME. Prognostic factors associated with locoronal relapses, metastatic relapses, and death among women with breast cancer. Population-based cohort study. Breast J. 2019; 48: 82-88. DOI: 10.1016/j.breast.2019.09.010

6- Billiard M. Fatigue and sleep disorders of patients with colorectal cancer. Pathol Biol (Paris). 2013; 61(5):e83-7. DOI: $10.1016 /$ j.patbio.2010.12.002.

7- Bingham SA, Luben R, Welch A, Wareham N, Khaw KT, Day N, et al. Are imprecise methods obscuring a relation between fat and breast cancer? Lancet. 2003; 362(9379): 212-4. DOI: 10.1016/S0140-6736(03)13913-X

8- Momeni M, Ghanbari Khanghah A, Joukar F, Kazem Nezhad Leili E. Predictive Factors of Quality of Life in Patients with Colorectal cancer. J Holist Nurs Midwifery. 2012; 22 (1): 44-53. [Persian].

9- Osmani F, Hajizadeh E, Rasekhi A, Akbari ME. Analyzing Relationship Between Local and Metastasis Relapses with Survival of Patients with Breast Cancer: A Study Using Joint Frailty Model. Int J Cancer Manag. 2018; 11(12): e81783. DOI: $10.5812 / \mathrm{ijcm} .81783$

10- Kidd L, Hubbard G, O'Carroll R, Kearney, N. . Perceived control and involvement in self care in patients with colorectal cancer. J Clin Nurs. 2009; 18(16): 2292-2300. DOI:10.1111/j.1365-2702.2009.02802.x

11- Qian H, \& Yuan C.. Factors associated with self-care self-efficacy among gastric and colorectal cancer patients. Cancer Nurs. 2012; 35(3), E22-E31. DOI: 10.1097/NCC.0b013e31822d7537.

12- Nikoletti S, Young J, Levitt M, King M, Chidlow C, \& Hollingsworth S, et al. Bowel problems, self-care practices, and information needs of colorectal cancer survivors at 6 to 24 months after sphincter-saving surgery. Cancer Nurs. 2012; 31(5): 389-398. DOI: 10.1097/01.NCC.0000305759.04357.1b

13- Miaskowski C, Dodd M, West C, Schumacher K, Paul SM, Tripathy D, et al. Randomized clinical trial of the effectiveness of a self-care intervention to improve cancer pain management. 2004; J Clin Oncol. 22(9): 17131720. DOI: 10.1200/JCO.2004.06.140.

14- Royani Z, Rayyani M, Vatanparast M, Mahdavifar M, Goleij J. The relationship between self-care and self-efficacy with empowerment in patients undergoing hemodialysis. Mil Caring Sci. 2015; 1(2): 116-22. [Persian]. DOI: 10.18869/acadpub.mcs.1.2.116.

15- Cassidy J, Tabernero J, Twelves C, Brunet R, Butts C, Conroy T, et al. Xelox (Capecitabine plus Oxaliplatin): active first line therapy for patients with metastatic colorectal cancer. J Clin Oncol. 2004; 22(11): 2084-2091. DOI: 10.1200/JCO.2004.11.069

16. Karimi S, Vanaki Z, Bashiri H, Hassani SA. The effect of Orem self-care ability of patients with colorectal cancer. Avicenna J Nurs Midwifery Care. 2016; 24(2): 105-112. DOI: 10.20286/nmj-24025. [Persian].

17- Khazaeipool M, Pasha N. The effect of self care education in Quality of life in esophagus cancer patients. Zahedan J Res Med Sci. 2010; 12 (4): e94291. 54-54. [Persian].

18- Afrasiabifar A, Hamzhiekia SH, \& Hosseini NA. . The effect of Self-Care Program Using Orem's Self-Care Model on the Life Quality of Women with Breast Cancer Undergoing Chemotherapy: A Randomized Controlled Trial. Armaghane danesh. 2018; 23(1): 1-13. [Persian].

19- Davarpanah M, Fayazi S, Shariati A, Mirhosseini SD. The Effect of Family-Centered Empowerment Model on the Quality of Life of Patients with Leukemia. Jundishapur J Chronic Dis Care. 2017; 6(1). DOI: 10.17795/jjcdc36441. [Persian].

20- Kidd L, Kearney N, O'Carroll R, Hubbard G. Experiences of self-care in patients with colorectal cancer: a longitudinal study. J Adv Nurs. 2008; 64(5), 469-477. DOI: 10.1111/j.1365-2648.2008.04796.x.

21- Auld ME, Hatcher MT. Environmental health promotion: advancing the science and practice. Health Promot Pract, 2010; 11(3): 301-346. DOI: 10.1177/1524839910364371. 
22- Boyd M A. Psychiatric nursing: Contemporary practice. lippincott Williams \& wilkins. 2008

23- Buhse, M. Assessment of caregiver burden in families of persons with multiple sclerosis. J Neurosci Nurs. 2008; 40(1); 25-31. DOI: 10.1097/01376517-200802000-00005.

24- Rezai Asl H, Seyyed Mazhari M, Pishgooi SAH, Alhani F. Effectiveness of "Family-Centered Empowerment Model" on the Treatment Adherence of Patients with Type II Diabetes and Heart Disorder Admitted to AJA Hospitals, During Year 2015. Mil Caring Sci. 2017; 4 (1): 58-69. [Persian]. DOI: 10.29252/mcs.4.1.58

25- Shirvani H, Alhani F, Montazeri A. The Effect of Family-centered Empowerment Model on the Functional Scales Quality of Life in Women with Breast Cancer Undergoing Chemotherapy. Iran J Breast Dis. 2017; 10(1): 61-72. [Pesrian]

26- Hamakera ME, Prins MC, Schiphorst AH, van Tuyl SAC, Pronk A, van den Bos F, et al. Long-term changes in physical capacity after colorectal cancer treatment. J Geriatr Oncol. 2015; 6(2): 153-64. DOI: 10.1016/j.jgo.2014.10.001

27- Bruns ER, van den Heuvel B, Buskens CJ, van Duijvendijk P, Festen S, Wassenaar EB, et al. The effects of physical prehabilitation in elderly patients undergoing colorectal surgery: a systematic review. Colorectal Dis. 2016; 18(8): O267-77. DOI: 10.1111/codi.13429

28- van Weert E, Hoekstra-Weebers J, Grol B, Otter R, Arendzen HJ, Postema K, et al. A multidimensional cancer rehabilitation program for cancer survivors Effectiveness on healthrelated quality of life. J Psychosom Res. 2005; 58(6): 485-96. DOI: 10.1016/j.jpsychores.2005.02.008

29- Yamano T, Yoshimura M, Kobayashi M, Beppu N, Hamanaka M, Babaya A, et al. Malnutrition in rectal cancer patients receiving preoperative chemoradiotherapy is common and associated with treatment tolerability and anastomotic leakage. Int J Colorectal Dis. 2016; 31(4): 877-884. DOI: 10.1007/s00384-016-2507-8

30- Yau T, Watkins D, Cunningham D, Barbachano Y, Chau I, Chong G, et al. Longitudinal assessment of quality of life in rectal cancer patients with or without stomas following primary resection. Dis Colon Rectum. 2009; 52(4): 669-77. DOI: 10.1007/DCR.0b013e31819eb970 